\title{
Toilet power: potable water reuse and the situated meaning of sustainability in the southwestern United States
}

\author{
Kerri Jean Ormerod ${ }^{1}$ \\ University of Nevada, Reno, USA
}

\begin{abstract}
Proposals to recycle urban wastewater for potable purposes are at the forefront of water development. In this article I combine political ecology's attention to networked relations with Q methodology to identify the shared positions of select stakeholders in the southwestern United States, an urbanizing region increasingly reliant on potable water reuse. I employ critical Q methodology to provide a contextual understanding of how water and sanitation technology shapes subjects and environments. The analyses reveal two distinct sanitary subjectivities, which I label neosanitarian and ecosanitarian, whose views most sharply diverge regarding the appropriateness of direct potable reuse and composting toilets. The findings highlight the situated meaning of sustainability and also underscore the role that wastewater and water reuse play in shaping ecologies, which in turn, helps to identify the environments of elimination that make specific innovations in the water sector possible. In conclusion, I suggest that in the broader context of potable water reuse, the toilet is in a perniciously powerful position to make city-spaces and shape the future citizenry.
\end{abstract}

Keywords: infrastructure, urban metabolism, Q methodology, water recycling, composting toilet

\section{Résumé}

Les propositions de recyclage des eaux usées urbaines à des fins potables sont à la pointe du développement de l'eau. Dans cet article, je combine l'attention de l'écologie politique sur les relations en réseau avec la méthodologie Q pour identifier les positions communes de parties prenantes sélectionnées dans le sud-ouest des États-Unis, une région en pleine urbanisation qui dépend de plus en plus de la réutilisation de l'eau potable. J'utilise une méthodologie Q critique pour fournir une compréhension contextuelle de la manière dont la technologie de l'eau et de l'assainissement façonne les sujets et les environnements. Les analyses révèlent deux subjectivités sanitaires distinctes, que je qualifie de néosanitaires et d'écosanitaires, dont les points de vue divergent considérablement en ce qui concerne la pertinence des toilettes à réutilisation directe et à compostage. Les résultats soulignent la signification localisée de la durabilité et soulignent également le rôle que jouent la réutilisation des eaux usées dans l'écologie, ce qui aide à identifier les environnements d'élimination permettant des innovations spécifiques dans le secteur de l'eau. En conclusion, je suggère que, dans le contexte plus large de la réutilisation de l'eau potable, les toilettes occupent une position extrêmement puissante pour créer des espaces urbains et façonner les citoyens de demain.

Mots-clés: infrastructure, métabolisme urbain, méthodologie Q, recyclage de l'eau, toilettes à compost

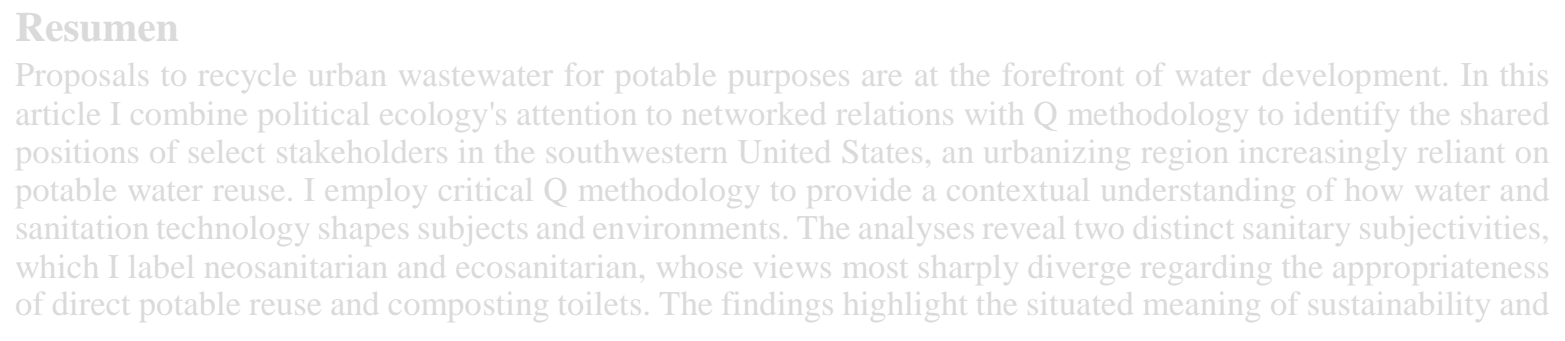

\footnotetext{
${ }^{1}$ Dr. Kerri Jean Omerod, Assistant Professor, Department of Geography and Cooperative Extension, University of Nevada, Reno, Nevada USA. Email: kormerod "at" unr.edu. This publication was developed under STAR Fellowship Assistance Agreement no. 91735701 awarded by the U.S. Environmental Protection Agency, 2011-2014. It has not been formally reviewed by EPA. The views expressed in this publication are solely those of the author, and EPA does not endorse any products or commercial services mentioned in this publication. The author would like to thank the study participants and Drs. Majed Akhter, Jessie Clark, Katie Meehan, and Katherine Hepworth for their comments and conversations.
} 


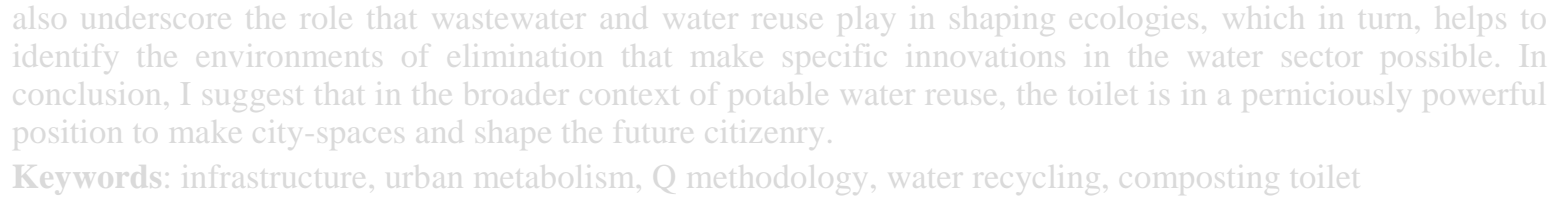

\section{Introduction}

Water planners faced with water supply or wastewater disposal pressures are increasingly willing to consider the utility of incorporating potable water reuse. Planned potable water reuse augments drinking water supplies with highly treated municipal wastewater, known as reclaimed (or recycled) water. The practice is made possible by advanced water treatment processes that transform urban sewage into a water resource that meets or exceeds drinking water standards (NRC 2012). As a result, planners view reclaimed water as an attractive urban water resource available for capture. In this article I employ Q methodology (hereafter Q) as an applied method to systematically study of subjectivity (i.e., viewpoints, preferences, opinions) in regard to planned potable water reuse. Q is a mixed-methods approach that combines statistical analysis with qualitative techniques to empirically outline and analyze subjectivity (Sneegas 2019). Scholars have applied Q to examine a range of subjective preferences including distinguishing between different notions of democracy, identity, and citizenship (Dryzek and Kanra 2014) and identifying competing environmental paradigms or discourses (Cousins 2017a; Jepson et al. 2012). In this article, I explore the recommendations that are held in common by people engaged in the governance of planned potable water reuse in the southwestern United States (Southwest) - a region at the forefront of potable water reuse (EPA 2017). Q is applied here to identify different shared perspectives (i.e., contingent subjectivities) and to explore the ways that water infrastructures make and shape subjects. The differences that emerge from the analyses illustrate how technologies script different types of behavior that, in turn, produce certain "sanitation subjectivities." I describe these subject positions to advance my argument that ordinary everyday objects, such as the common toilet, have the power to make city-space and shape the citizenry, in addition to altering environments and ecologies.

This article provides additional analysis of the first known study to employ Q to study the subjectivity of people with interests or connections to reclaimed water in the Southwest, which indicated two competing perspectives regarding the principles that should guide the future of potable water reuse. The primary quantitative findings from this study have been published previously, which includes the factor loading table (i.e., each respondent associated to common groups through a statistically significant score) and the full statement set with factor scores for each perspective (i.e., contrasting the distinguishing and salient statements between factors) (Ormerod 2017). The results presented in this article focus on the qualitative data to develop rich descriptions of the subjectivity of the study participants: people who are particularly knowledgeable about urban water supply, water disposal, and water reuse options in the Southwest. In doing, this article contributes to the emerging field of "critical Q" scholarship (Sneegas 2019: 1), which integrates Q statistics with discourse analysis to understand how people align into shared worldviews (Cousins 2017a; Iribarnegaray et al. 2014; Jepson et al. 2012; Sneegas 2019; Ward 2013; Lehrer and Sneegas 2018; Nost et al. 2019). The remainder of this article proceeds in five parts. In the following section, I briefly discuss how political ecologists have recently theorized the relations between urbanization, subjectivity, and infrastructures. Next, I describe the process of potable water reuse. I then describe procedures in Q and the means used to identify shared subject positions in response to potable water reuse. The results follow, which outline the subjective positions of key actors engaged in reclaimed water governance. In the penultimate section, I discuss specific environments of elimination and trace the role that effluent plays in two communities in the Southwest. In conclusion, I touch on the implications of the different subject positions for future water governance.

\section{Urbanization and socio-ecological relations}

Urban political ecologists often explain environmental change as a form of socially mediated "natural" metabolism, which highlights how culture, people, and technology intersect and interact to shape interdependent 
relations between nature and society, including how water and sewage connect the city to distant places (e.g., bodies, environments) (Cousins 2017a; Cousins 2017b; Radonic and Kelly-Richards 2015). Urban political ecologists also increasingly recognize infrastructures, such as energy, water, wastewater, and transportation systems, "structure a major part of the material metabolism in industrialized societies" (Monstadt 2009: 1926). But, as Doshi explains (2017), metabolism is more than a material metaphor - it is an embodied politics (that includes defecation), which acknowledges socio-spatial inequality, interconnected relations, affect and emotion, and differentiated experiences.

Political ecologists often consider water infrastructure as part of an assemblage, which is a conceptual tool that is used describe connected local and global, social and physical environments, or networks. Assemblage thinking aims to overcome human-centered accounts and binarized conceptions of the world (e.g., subjects/objects, nature/society) to provide for a networked analysis that embodies the material and the representational (Robbins and Marks 2009). Robbins' (2007) Lawn people takes assemblage as a theoretical platform to describe nature's role in forming certain kinds of communities. The networked analysis in Lawn people is attentive to uneven social relationships, patterns of land use, and the difference that non-human "nature" makes (Robbins 2007). In doing, Robbins makes the connectivity between everyday behaviors and broader environment explicit by tracing how the very ordinariness of disaggregated individual daily decisionmaking about American lawn maintenance is connected to broader political and economic forces. The American lawn may appear benign, however these everyday choices about chemical inputs and turf grass management contribute to vast urban ecological problems.

Assemblage-inspired analyses acknowledge that individual choices are structured within larger sets of networked relations between humans and non-humans. Robbins and Marks (2009: 183) suggest that we might consider sewers as a prime example of an urban assemblage:

Nothing seems more human, more controlled, more deliberate, or more volitional that urban infrastructural development. Conceived at the drafting table, paid for and argued over in city council meetings, and laid out by engineers, the key to understanding them and their role in urban geography typically lies in understanding problems of annexation, struggles over suburban growth, historical constructions of the sanitary city, and political debates over effluent discharge in the face of economic development and rising ecological consciousness. Sewage is an inherently social phenomenon, suffused with capital, politics, and systems of meaning-making.

Assemblage thinking stresses that sewage can be "disciplined", but it also acts on own, it is unruly, uncooperative, and is not completely under human control (Robbins and Marks 2009).

Contemporary political ecologists frequently acknowledge the social power of various infrastructures as a means to explain human-environment relations, including rainwater collection (Meehan 2014), desalination (McEvoy 2015), stormwater capture (Cousins 2017a, 2017b), urban water reuse (Ormerod 2017), and composting toilets (Radonic and Kelly-Richards 2015). As a result, political ecologists often propose that "[i]nfrastructures act in the world in ways that both co-produce the operation of power while also opening up space for material contestation" (Millington 2018: 28). For example, Meehan (2014: 215) proposes understanding water infrastructures as "nonhuman power brokers" with varying degrees of "tool power", a means of acknowledging shared and uneven power relations. Her object-oriented approach allows scholars to understand nonhumans as "wellsprings of power" or "power brokers" in the urban water sphere.

In the case of potable water reuse, a set of key actors are in a privileged position to shape the waterscape of the Southwest: both human and non-human. The humans in the most privileged position are the planners, engineers, scholars, operators, consultants, and environmentalists who currently work at the forefront of water governance. The non-humans in the most powerful position are the flush toilet and the sanitary sewers. The toilet consumes a large share of domestic water supplies and, therefore, is a major supplier of wastewater, which is reclaimed water's parent supply. Before exploring how water infrastructure makes and shapes the cities and citizenry, a very basic explanation of a proposed change in infrastructure is essential. 


\section{Pursuing potable water reuse}

Environmental engineers propose potable water reuse as a solution to two increasingly common challenges of urbanization: water supply and wastewater disposal (EPA 2017). Supplementing drinking water with recycled water solves problems of water quantity and quality via advanced water treatment processes, which are applied after conventional wastewater treatment and can produce water that exceeds state and federal drinking water standards. Advanced water treatment typically includes microfiltration and reverse osmosis along with additional engineered processes. Next, the recycled water is added to drinking water supplies either indirectly, or directly. Indirect potable reuse (IPR) involves blending recycled water within a natural system, such as groundwater or surface water reservoirs, before delivery. More recently the practice of direct potable reuse (DPR) is gaining attention from water planners (EPA 2017). DPR involves adding recycled water to municipal drinking supply without using an environmental buffer (i.e., directly from plant to pipe). Given layers of additional treatment and testing, experts consider potable quality recycled water to be as safe, if not safer than, conventionally sourced water supplies (NRC 2012).

From a pure engineering perspective, potable water reuse is more efficient than non-potable alternatives (e.g., irrigation, industrial use) because it utilizes existing infrastructure. Engineers also consider DPR more efficient than IPR because it reduces the capital and energy costs of expanding reclaimed water utilization. Prior to the recent wave of interest in DPR, IPR projects were the dominant form of planned potable reuse (EPA 2017). Although planning for potable water reuse has become steadily institutionalized over time, its application remains highly uneven and most operational projects are in the United States (US) and remain concentrated in or around coastal California (EPA 2017). Facilities in southern California have served as moral, political, intellectual leaders on potable water reuse, however most of the IPR systems were established decades before public consultation was considered critical to project success (Ormerod 2016). Despite industry acceptance, the current state of public acceptance in most places is unknown. The possibility for public objection remains a looming threat for projects planned across the Southwest and beyond (EPA 2017; Fielding et al. 2018; Meehan et al. 2013).

Scholars have recently called for more nuanced approaches to understanding and overcoming "conventional duopolies" in the water sector, which oppose two ways of thinking (such as market-based vs. government regulation approaches to managing risk), in favor of accounting for a pluralistic rationality (Beck et al. 2018). Q provides one way of identifying different forms of rationality in regard to potable water reuse. In this study, I employ Q to determine common patterns of responses of select stakeholders engaged in water governance in the Southwest, which is used to identify shared perception profiles.

\section{Q Methodology}

Scholars employ Q to identify parameters of shared understanding (Buchel and Frantzeskaki 2015; Cousins 2017a; Jepson et al. 2012; Sneegas 2019) or, more accurately, "significantly different assemblages of claims" (Robbins and Krueger 2000: 369). Performing a Q study typically involves six steps: selection of statements related to the topic of under investigation, development of the Q sample (the limited number of statements used for data collection), selection of the study participants, Q-sorting procedure (in which participants rank the selected statements), correlation and factor analysis, and interpretation (Watts and Stenner 2012). Unlike traditional surveys, which limit inquiry to the predefined essentialist categories (e.g., men/women, opponent/proponents), Q enables categories of difference to arise from the data (Eden et al. 2005; Watts and Stenner 2012). Participants in Q studies indicate their position by rank-ordering a series of statements (or some other stimuli) in a forced distribution based on the degree to which they agree with each statement (i.e., according to their subjective preferences). The act of sorting all statements relative to one another demonstrates the participant's subjective point-of-view. In this respect, participants "define themselves through the sort, rather than being placed by the researcher in predefined categories" (Nost et al. 2019: 24; emphasis in the original).

Methodologies for representing social phenomena are typically thought of as either deductive or inductive but $\mathrm{Q}$ is neither an inductive theory-building qualitative technique, nor is it a deductive theory-testing technique. Q is an abductive method (Watts and Sternner 2012). Abductive methods employ abductive 
reasoning to determine plausibility based on a set of evidence and judgment based on the knowledge of the researcher (for detailed explanation of abductive reasoning in scientific discovery and explanation see Aliseda 2006). Abductive reasoning is an iterative interpretative process that involves thinking from effects to causes, which requires background knowledge and experience to constrain the field of possible explanations. Medical diagnosis, crime scene investigation, and scenario planning are examples of applied abductive methods.

Q does not require a large sample size to produce statistically significant results due to the holistic and relational form of data collection (i.e., rank-ordered Q sorts). However, since it does not produce inferential statistics, one of the limitations of $\mathrm{Q}$ is that cannot provide any information about the prevalence of these perception profiles in the community. Therefore, generalizations cannot be drawn from the Q sample to the general population (see Watts and Stenner 2012 for detailed description of the statistical principles involved). As an intensive study of subjectivity, Q reveals different ways of thinking about an issue or problem and helps to explain "why and how people believe what they do" (McKeown and Thomas 1988: 45). Q is an adept methodology for issues of public policy because it can empirically establish areas of consensus and identify the limited number of distinct shared social perspectives.

Data collection for this study included site visits, Q surveys, and semi-structured interviews. From 20112015, I took part in eight public demonstrations or guided tours (e.g., Orange County Water District's Groundwater Adventure Tour, San Diego's Water Purification Demonstration Project) and attended or participated in four specialty conferences or workshops related to water reuse. I collected the Q survey data online due to the specialized topic and spatial extent of potable reuse in the Southwest. Most of the interviews took place over the telephone.

The potential participants for this study included people with known interests or connections to potable water reuse in the Southwest, which included elected and appointed officials, water planners, managers and regulators, nongovernmental organization (NGO) staff, water and sewer utility district directors, administrators, engineers, operators, citizen advisory board members, activists, resource planners, consultants, and research scientists. This entailed identifying 150 key individuals (e.g., public information officers, consultants, technicians, environmentalists, academics, planners, engaged citizens) to recruit from academic and policy publications, industry conferences, internet searches, public meetings, and media coverage in the southwestern US with particular attention to Arizona and California.

All but one of the survey participants were sent an email invitation to participate in the study that included a link to the online survey using POETQ (Jeffares et al. 2012), which is a tool developed specifically for gathering Q-sort data. One respondent received an invitation via US Post because an email address was not publicly available. Survey participants were not asked to identify other potential respondents; however, some participants contacted me to suggest people whom they thought would be interested in participating in the survey. Additional invitations were emailed to individuals recommended by survey participants that met the study criteria. In total, 176 individualized invitations were sent to experts, specialists, and engaged citizens (e.g., citizen advisory board members, environmental advocates) in 2014.

In total, 41 people completed the survey (including myself). The 41 participants include academics, consultants, people engaged in regulation (at the local, state, and federal levels), environmental advocates, communication managers, engineers, and others (see Ormerod 2017 for full list of job descriptions). Overall, 19 participants resided in Arizona, 18 in California, and four resided outside of Arizona or California. Several participants indicated broad geographic professional expertise or interests, which included Arizona, California, Florida, Texas, Singapore, Australia and beyond. The participants associated with environmentally-oriented non-profit organizations in California are primarily concerned with protecting fresh and coastal water resources, or opposed to desalination; in Arizona these organizations have interests in conservation of natural resources (e.g., birds, mountains, watersheds) especially, but not exclusively, in the Sonoran Desert region. In addition, I interviewed 23 of the participants to validate the findings and contextualize results.

The Q survey included 30 recommendations related to potable water reuse, which were refined from statements presented in popular media, specialty conferences, academic publications, trade journals, and other public forums (e.g., public comments made in open forums or during plant tours). Following procedures typical in Q studies (McKeown and Thomas 1988; Watts and Stenner 2012), the survey prompted participants to sort 
each statement, relative to all others, on a bell-shaped scale ranging from -3 (more disagreeable) to +3 (more agreeable). Next, the completed Q-sorts are factor analyzed, significantly loading Q scores are merged and the researcher interprets possible factors. The purpose of this relational approach to data collection is to reveal shared ways of thinking (Watts and Stenner 2012).

I performed the statistical analyses using PQMethod, which is a software package designed specifically for Q (PQMethod 2014). The individual Q-sorts were factor analyzed using centroid extraction with varimax rotation to identify to define commonly held views. Factor loadings of \pm 0.47 or above were significant at the $p<0.01$ level following the formula identified in Watts and Stenner (2012). The $p<0.01$ value is typical in Q studies; it indicates there is a $99 \%$ probability that the arrangement of statements between the factors is statistically significant (i.e., they are significantly different) (Watts and Stenner 2012). In Q studies, the number of distinct perception profiles (i.e., number of factors) emerges from the analyses and cannot be determined in advance. Interpretation requires qualitative analysis that prioritizes theoretical over statistical significance (McKeown and Thomas 1988). Characteristically, two or more people define a factor in a Q study because Q is used to measure commonality and represents shared understanding.

In this study, 35 respondents share one of two distinct subject positions (i.e., cohere into two factors) regarding the principles that should govern the future of potable water reuse, which are described in greater detail below. The qualitative analyses synthesized similarly aligned participants' recommendations about planned potable water reuse into shared subject position. The six idiosyncratic responses included two university professors, one unaffiliated public citizen, one person affiliated with an environmental NGO in northern California, and myself. I do not discuss the views of these six respondents because they are each unique in their own way.

\section{Results: shared subject positions of select toilet people}

The two different subject positions that emerged from this study highlight distinct water infrastructure preferences for key stakeholders. For simplicity, I've labeled these positions as neosanitarian and ecosanitarian. The neosanitarian position (32 participants) supports all modes of potable water recycling, including DPR $(n=32)$. I've labeled this group neosanitarians because their view embraces many of the material and representational maxims of modern sanitation - including a reliance on wastewater treatment technology to protect public health and the environment. The neosanitarian subject position is well formed and widely supported by the water and wastewater industry and related stakeholder communities. The alternative view in this study is comfortable with potable water recycling but ideally prefers composting toilets as a preventative approach to improving urban water quality and quantity (3 participants). I use ecosanitarian to describe this group because they favor holistic and ecological solutions to dealing with human excrement, such as composting toilets. By comparison, the ecosanitarian subject position is nascent, rather loosely formed, and not championed in the water or sanitation industries.

Neosanitarian and ecosanitarian perspectives overlap on many issues despite divergent perspectives on what the ideal sanitation system should look like. In total, they ranked $40 \%$ of the 30 recommendations in a significantly similar fashion, which indicates a fair amount of consensus. Overall, these neosanitarian and ecosanitarian positions both disagreed with the following statements:

- Potable reuse should remain an option of last resort, considered only after all other measures have been evaluated and rejected $(-3,-2)^{2}$

- Recycled water should never be intentionally added to the drinking water supply $(-3,-2)$

To a lesser extent they also mostly agreed with the following statements:

\footnotetext{
2 The first number identifies the relative rank for the generalized neosanitarian subject position; the second indicates the rank of the statement for the ecosanitarian subject position.
} 
- We are going to drink recycled water one way or another; I believe we should do it through engineered systems where we can actively control the process $(+2,+2)$

- We need a more sustainable approach that takes into account factors such as energy and nutrient recovery, not just water recovery $(+2,+2)$

The neosanitarian and ecosanitarian subject positions are distinct, however they share the view that planned potable projects are feasible and may be preferable to alternative options for expanding regional water supplies.

Although there is a statistically significant level of agreement regarding the suitability of planned potable water recycling generally, there are sharp and significant contrasts regarding the suitability of DPR and composting toilets - the very technologies that were most important to each group.

The neosanitarian and ecosanitarian share appreciation for alternative technologies but it is their dissimilarities that reveal distinct forms of subjectivity and the situated meaning of sustainability in the Southwest. These dissimilarities are based largely on competing views of the ideal future technologies, one high-tech and one low-tech, which prescribe two competing forms of hydropolitics, which are described in greater detail below.

Neosanitarian toilet people: quality, not history

The neosanitarian view (32 participants) is focused on water quality and the respondents represent a wide range of stakeholders including communication and public information officers, technical and nontechnical consultants, water planners, hydrologists, engineers, academics, regulators and compliance mangers, water and wastewater utility directors, professionals employed by environmental non-profit organizations, and others. The participants that identified with the neosanitarian subject position mostly lived and/or worked in California or Arizona but a few primarily worked or resided in other states in the US.

The two statements this generalized neosanitarian view agreed with most when considering what principles should govern the future of planned potable reuse were:

- Direct potable reuse should be considered alongside other options $(+3,-2)$

- Water should be judged by its quality, not its history $(+3,0)$

The two statements this generalized neosanitarian view disagreed with most were:

- Recycled water should never be intentionally added to the drinking water supply $(-3,-2)$

- Potable reuse should remain an option of last resort, considered only after all other measures have been evaluated and rejected $(-3,-2)$

These are statements that ecosanitarians also disagree with, however the statements they mostly agreed with were distinct to neosanitarian subject position and helps to define this perspective as distinct from the ecosanitarian view.

Recall that DPR blends reclaimed water with traditional water supplies at the drinking water treatment plant, unlike indirect projects that rely on intermediate rivers, reservoirs, or groundwater aquifers for blending. When asked to explain support for DPR, people with this view expressed a certain comfort based on everyday interaction water infrastructure. For example, one communication manager in California stated,

I agree because I work in the industry, understand the process, and most importantly participate in the meetings where I personally witness the experts, regulators, and utility [representatives] take great pains to ensure the protection of public health through the treatment process, source control, and other means (R7). 
This comment illustrates confidence in DPR is based on situated relationships, which neosanitarian subjects reflected upon across scales considering current conditions. Several neosanitarian-aligned respondents felt DPR was a prudent choice within the context of water and disposal infrastructure. For example, one project manager from Arizona stated,

Because it provides a cost-effective way to treat and deliver recycled drinking water using one distribution system without compromising quality (R34).

Similarly, a policy director who worked for a non-profit in California stated,

With proper failsafe technologies, DPR can cut down on conveyance infrastructure while still ensuring an adequate and safe drinking water supply (R20).

A hydrologist in Arizona concurred,

Current technology can consistently assure a very high quality ... much more consistent than the quality of water that currently enters drinking water treatment plants, especially from surface water sources (R41).

Proponents of DPR suggest it is just one of many possible ways to utilize reclaimed water. A utility director in Arizona noted that,

Technology exists today that would allow water utilities the ability to 'design' the type of water their community may be able to use (R3).

Indeed, a relevant example is the Edward C. Little Water Recycling Facility in California, where secondary treated effluent undergoes additional water treatment processes to produce five different gradients of designer water. This "fit-for-purpose" reclaimed water is sold for both potable and non-potable purposes.

For those who hold a neosanitarian position, DPR ensures efficient delivery of a high-quality product and that is sufficient reason to use reclaimed water as a substitute water supply for potable or non-potable purposes. Furthermore, as the replies above suggests, once the initial infrastructures are laid, social, economic, and cultural institutions work to inscribe and entrench a fundamental commitment to established sanitation systems.

The neosanitarian subject strongly agrees with the phrase "water should be judged by its quality not its history", which is used frequently by proponents in an attempt to dislodge public unease with drinking reclaimed water. In their view, any opposition to potable water reuse is an issue of public perception and/or a lack of general understanding of the safety of reclaimed water. The fact that technology can control quality lends to the neosanitarian confidence in engineered solutions over social or behavioral fixes. Reflecting on support for this statement an engineer in southern California claimed,

At some point in time a particular drop of water has been in every possible situation. After nature evaporates water from a sewage holding pond and rains it down in a secluded mountain it is most likely clean. We, especially in the Southwest, are already drinking recycled water directly from upstream users. This water is fine for the public because generally speaking we don't know its history. We, the public, base its acceptance on its quality. So why not base the acceptable of all water on its quality? (R8).

Another respondent opined, 
Just because the label says the water comes from a natural spring in some exotic land doesn't mean a bird hasn't pooped in it or a bug hasn't died in it at some point. All water has stuff in it, good or bad. I'm happy knowing that all the bad stuff has been removed using the highest standards possible and best technologies. The quality is important. Or stated another way, I don't care if my brain surgeon grew up in a war-torn third world country with massive pollution and a high murder rate. If he's the best surgeon there is, with extensive training and qualifications, I'll trust him with my life. Same with my water (R7).

These replies indicate a clear preference for judging the suitability of potable reuse on the capacity of new technology to improve water quality, measures that are based on capital-intensive technical procedures.

Those who are aligned with the neosanitarian view are very familiar with advanced water treatment facilities, many of which are open for public tours that emphasize the safety measures employed to protect public health. For example, the control room at West Basin's Edward C. Little Water Recycling Facility, seen in Figure 1, serves to demonstrate the intense application of water treatment and monitoring. West Basin's recycling facility is one of a number of treatment facilities in the Southwest that can be toured in-person or online. Behind the glass in the foreground, the operators remotely supervise the production process including acquisition control, treatment controls, and the distribution system.

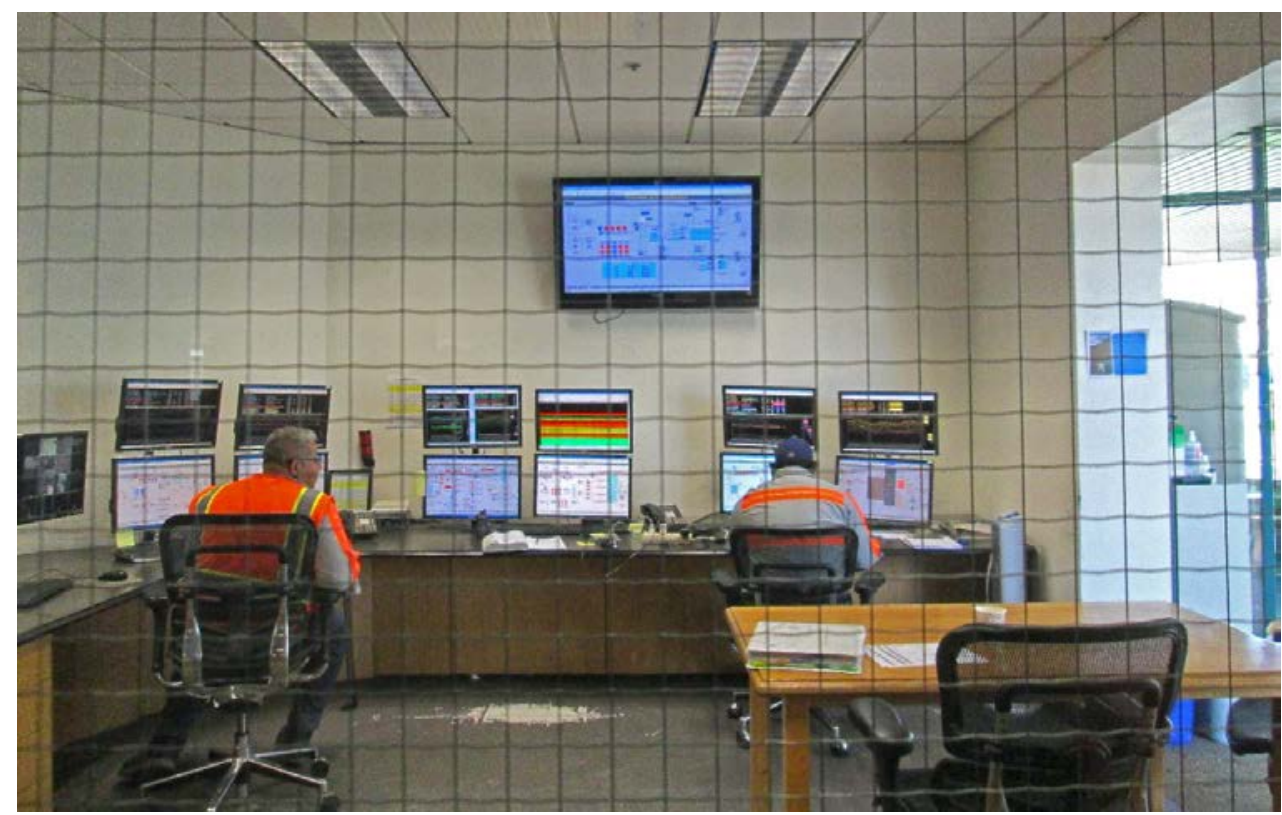

Figure 1: West Basin's Edward C. Little Water Recycling Facility Control Room, California. Photo by author, July 2014.

The neosanitarian subject position supports full utilization of current water supplies and subsequent resource recovery (e.g., reclaimed water, methane, various minerals and metals) at the wastewater treatment plant. Their penchant for potable reuse is not wholly surprising since many neosanitarian respondents indicated memberships in professional organizations that promote water and wastewater treatment solutions (e.g., National Association of Clean Water Agencies, the Water Environment Research Foundation). In sum, pragmatism, feasibility, costs, comfort, and familiarity with sanitation and water recycling are reasons given for holding the neosanitarian subjectivity. 


\section{Ecosanitarian toilet people: Mother Nature is pissed}

The ecosanitarian view (3 participants) includes respondents who are comfortable with potable water recycling. but ideally prefers composting toilets. All the respondents who shared this perspective lived in southern Arizona, were associated with separate non-profit organizations (both environmental and social justice), and extended themselves to their communities through various acts of public service and volunteerism.

When considering what principles should govern the future of planned potable reuse the two statements that the generalized ecosanitarian view found most agreeable were:

- Ideally, we'd all have self-contained composting toilets, this would remove human waste from urban water infrastructure entirely $(-2,+3)$

- Potable reuse is a public issue that needs lots of community debate before any decisions are made $(0,+3)$

The two items ranked most disagreeable were:

- Business groups should be actively involved in decisions regarding the future of potable water reuse $(+1,-3)$

- The water utility should determine if and how potable water reuse is pursued $(-1,-3)$

The participants aligned with the ecosanitarian subjectivity are confident in water treatment technologies, however they are not satisfied with the status quo solutions to urban water problems. Reflexive about what toilet connects and disconnects, their view suggests we ought to change course considerably and prioritize dry sanitation. As the director of a regional environmental non-profit group stated,

Reducing the use of materials, and recycling materials we use, is the most sustainable way to live. This provides nutrients for plant growth and eliminates water use (R28).

Similarly, the president of another environmentally focused nonprofit explained, "It just makes sense to not dilute humanure with fresh water." (R30). In their view urban water problems are urgent and flush toilets are a wasteful abuse of water as well as all the other natural resources found in urine and feces, including nitrogen, phosphorus, and potassium.

The ecosanitarian position is forward looking. They want water planners to allow for flexible methods of managing sanitation in the city so that urbanites have a choice not to be waste-makers and, instead, to be resourceful ecosanitarian toilet people. The subject position is suspicious of profit-seeking behaviors and the influence of land developers and related interest groups. As suggested by one respondent,

Business groups, especially the growth industries, will want to maximize revenues, typically short-term revenues, with little thought for our long term community well-being. The small community-based businesses will typically have less say than larger companies with less stake in the future of our communities (R30).

Another stated,

I don't believe that business has the best interest of the general public at heart. Business has a goal of making money for shareholders. When business reforms to serve for the public good I will reassess my answer (R28). 
From the ecosanitarian point of view, planners should strive to meet the needs of the future citizenry instead of the local land developers. In addition, the ecosanitarian view stresses a need for working collaboratively in the planning processes. As one participant explained,

It's not that water utilities shouldn't determine, rather, they alone should not have sole authority without setting in place strong measures for public participation in tandem, perhaps, with regulatory agencies - watch dogs (R24).

As these quotes imply, these respondents prefer to undo the legacy of expert-driven hierarchical sanitary solutions, rather than building on and extending them.

Cognizant of tipping points in the environment related to overexploitation and waste-making behaviors, those with the ecosanitarian view believe the time for change is nigh, as one interviewed respondent submitted ruefully, "Mother Nature is pissed" (R30). In their view, composting toilets offer a unique possibility for a more progressive, low-tech, hydropolitics, which decentralizes water and sanitation infrastructures and redistributes power by enrolling the average citizen into the network of sanitation.

Those aligned with the ecosanitarian subjectivity are acquainted with the benefits of excrement and decentralized sanitation technologies, which marginally are expressed in the lived environment in southern Arizona. One of the more remarkable examples is the Milagro Cohousing Community, which can be toured by appointment. The residents of Milagro collectively acted as the developer (e.g., corporation) in order to design their own intentional community in suburban area of Tucson known as the West Side - situated between the Santa Cruz River and the foothills of the Tucson Mountains. At Milagro residents reuse and manage their wastewater on-site using artificially constructed wetlands. The entire community relies on the wetlands for wastewater treatment and therefore residents must be mindful about what goes down the drain (e.g., no pharmaceuticals, toxics, feminine hygiene products), which necessitates a general understanding of the urban water cycle from the community. The residents maintain the wetlands in the corner of the community's media room, which is adjacent to the communal commercial kitchen, as pictured in Figure 2.

The ecosanitarian solution seeks to reduce the dependence on expertise and expert system by simplifying sanitation and slowing urban metabolism. Sites like Milagro demonstrate waste reducing and energy saving future possibilities. For example, the Milagro constructed wetlands were designed by and are managed by the community. The flexibility of the sanitation system allows the community to shut down the supply of water to one of the two treatment beds during the summer months. The change is temporary, and free. The wetlands also provide chemical, biological, and social benefits (e.g., habitat, groundwater recharge).

The ecosanitarian is interested in public participation and composting toilets, which suggests shifting toward more decentralized water conservation practices beyond what is practiced at Milagro, whose residents rely on low-flow flush toilets. For ecosanitarians, rethinking sanitation is key to solving complex and interrelated social-ecological issues. For them, dry sanitation is plainly the most resourceful response to the assorted pressures of continued urbanization. Reasons given for having this point-of-view include long-term well-being of the human and non-human community (e.g., birds, trees, fish, watersheds) and an interest in a more sustainable use of local resources, including water, people, and excrement. As stated by one ecosanitarian respondent,

The heart of activism is to understand natural limits rather than just technology... [we] must look at the water energy nexus, look at it all together, we can't have everything in silos, we must have a more nuanced debate ... We need this kind of work to help consensus building...[we] need to engage youth and create jobs (R24). 


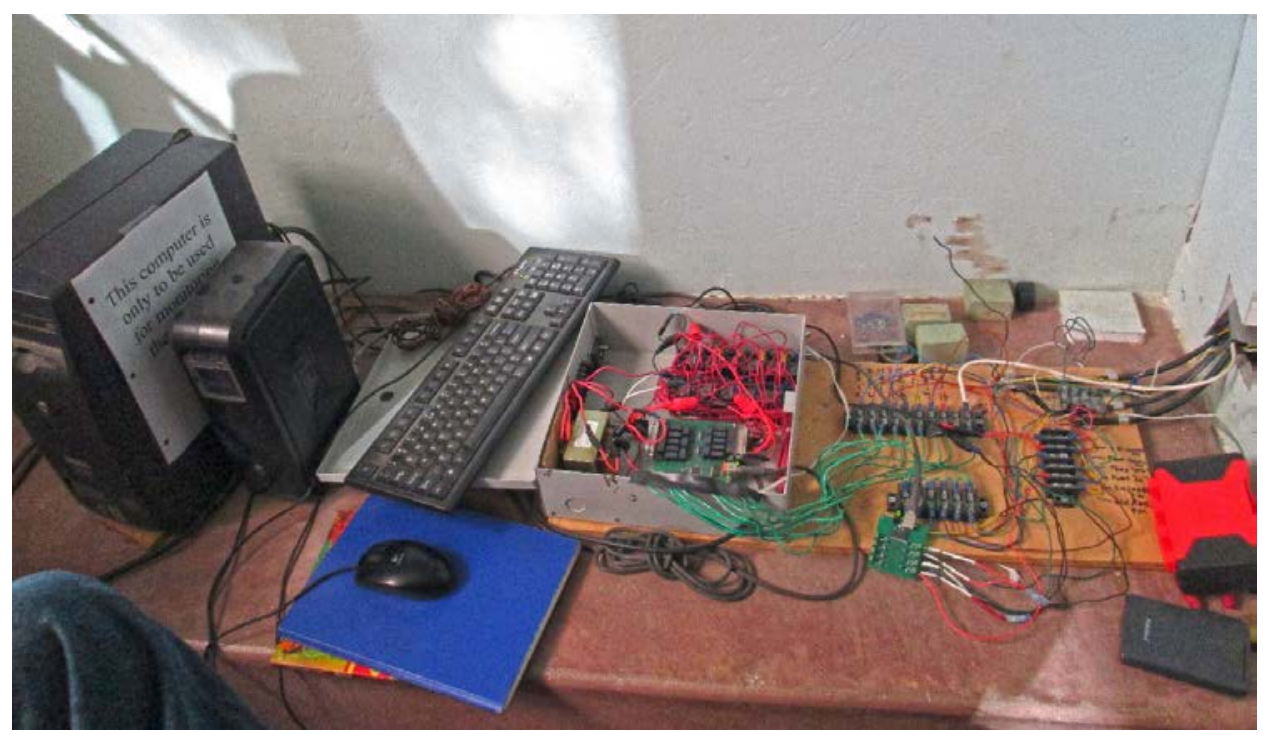

Figure 2. Milagro Cohousing Community's wetlands monitoring. The sign on the computer tower reads: "This computer is only to be used for monitoring the wetlands." Photo by author, July 2014.

The ecosanitarian subject position stresses that our bodies are connected to the body politics and the broader environment. They believe the re-imagination urban complexes can facilitate the introduction of new toilet technologies that could ultimately lead to more equitable future communities and healthier ecologies. Instead of re-inscribing the status quo, they seek to reconfigure collaborative (eco)sanitarian toilet subjectivities by drawing attention to the connectivity between daily behaviors and larger environment and by explicitly and clearly evaluating the utility of the common flush toilet within the broader moral arguments related to sustainability. They view the transition to composting toilets as adopting a holistic approach to sanitation that will result in nutrient recovery, reduced energy consumption, increased jobs, restored soils, and greater access to healthy food.

\section{Situated sustainability and environments of elimination}

The participants in this study are people who seek to influence design of socio-technical systems for water recycling, people with occupational experience, academic interests, or public interests, such as water planners, research scientists, and civically engaged citizens. They are familiar with urban water and wastewater treatment technologies and understand the collective impact of individual choices (e.g., medications, outdoor vs. indoor uses) on water and wastewater quality and quantity. In this respect, the respondents' conceptions of urban metabolism, and the potential cascading effects for the network of connected humans and ecosystems, are atypical and are not representative of the broader public's understanding. The respondents in this study understand that the specific forms of urban metabolism connect urbanites to differing institutional and biophysical constraints.

The images above help to illustrate how people are enrolled in different toilet networks that exhibit uneven levels of tool power. In this study, there was generalized agreement on the possible benefits of IPR to secure water supplies. In contrast, there was sharp disagreement on the benefits of DPR or composting toilets. The preference for composting toilets enrolls a wide variety of actors (human and nonhuman) into the sphere of sanitation that would require new socio-ecological urban systems as an alternative to hierarchical sociotechnical infrastructures. The majority of the interviewed participants who held a neosanitarian view were alarmed by the ecosantarian appreciation for dry sanitation. When informed that all the ecosanitarian 
respondents resided in Arizona, several of these participants noted specific geographic differences in water governance that help to explain their point of view. As one professor in Arizona explained it,

My first reaction is that it sounds like Tucson, [where] a large group of people are looking at alternative ways of using water and energy. Not that others don't think of it - but Tucson is populated by individuals who solve problems by their own actions. It doesn't surprise me since there is a lot of that going around. The individual interested in the watershed takes a larger social perspective (R15).

Another professor in Arizona similarly stated,

Southern Arizona has also gravitated more toward greywater, [it has] a larger more environmental perspective, composting toilets are more tangible there, [it's] greener, more locally-invested, as evidenced by the Watershed Management Group [Tucson-based non-profit that promotes community-based solutions such as water harvesting and composting toilets] (R23).

Despite these somewhat sympathetic characterizations, several respondents were also rather critical and dismissive of the ecosanitarian preference for composting toilets and characterized the idea as unworkable, "whacky" (R14), "Pollyanna, pie in the sky approach" (R22), or simply commented there is "[n]o possible alternative to the flush toilet, [it's] not possible" (R26).

The participants with an ecosanitarian view agree that the unique situation in southern Arizona helps to explain their subject position. For example, a director of a local non-profit, claimed it was an understandable response because people in Tucson "have a clue. ... [because] we've been through it" (R30). He then continued to detail what he meant by 'it': groundwater pumping, overdraft conditions, the drying up of the Santa Cruz River, long distance connections to imported Colorado River supplies, declining local water quality, nonstop urban development, expansion of mining operations, and continued agricultural use. For the ecosanitarian respondents, the availability of clean, potable water is a political and moral issue. Their view offers a rare challenge to sanitary systems that prompt urbanites to flush and forgo responsibility, however their position is embryotic and largely subordinate to the hegemonic neosanitarian view. They aim to change consciousness about what constitutes waste by reconfiguring sanitary subjectivity toward more emancipatory social relations that embrace effluent and excrement.

\section{Discussion}

The primary contribution of this study was to apply Q methodology to empirically explore the shared subjectivities of select stakeholders regarding potable water reuse in the Southwest. The application of Q facilitates a relational comparison, which provided a nuanced and empirical approach to understanding interconnected relations and different subject positions. The findings reveal remarkable consensus on the possibility for IPR but there is sharp disagreement regarding the appropriateness of DPR or composting toilets. The differences between neosanitarian and ecosanitarian subjectivities illustrate how different technologies script different types of behavior with substantially different material exchanges (i.e., flows of matter and material energy), competing urban metabolisms that are best represented by the ideal 'plants' (i.e., technologies) each proposes as part of the solution.

The neosanitarian subject position is primarily interested in water treatment plants and mechanical processes, though not to the exclusion of non-mechanical natural processes (e.g., soil-aquifer-treatment, constructed wetlands). The acceptance of DPR may seem ambitious to the average citizen, however DPR is an alternative that is positioned to make gains in the coming decades. The neosanitarian technological solution requires no modification of behavior for the average urbanite and minimal, if any, policy changes. This position seeks to adjust and reshape existing infrastructures, solutions, and ecologies in comparatively small ways.

The ecosanitarian subject position is primarily interested in composting toilets and the capacity of natural systems to treat human excrement, though not to the exclusion of mechanical processes (e.g., water treatment 
for drinking water systems). This position reflects a preference for decentralized and low-tech solutions such as composting toilets, xeriscaping, and rainwater harvesting. They are seeking transformational solutions that will reorder current urban systems and redefine conceptions of waste. The commitment to composting toilets may be unexpected to the neosanitarian, however not that long ago rainwater harvesting and stormwater capture were considered 'hippie' and fringe ideas and yet today these water saving technologies are legally permitted, encouraged and, in some instances, mandated in southern Arizona (Radonic 2019). In contrast to the number of neosanitarian public demonstration sites, the ecosanitarian demonstration sites are less technologically spectacular, or yet to be developed.

Those who hold an ecosanitarian view favor collective decentralized sanitary solutions over the centralized and hierarchical services that are currently in place. The alternative sanitation system that they propose enrolls the average urbanite in the network of actors engaged in sanitation and, furthermore, recognizes the new subject positions that emerge from the use of composting toilets. The successful urban models of dry sanitation in the US could improve access in unsewered, often overlooked, communities in the US (Feinstein and Daiess. 2019; Speer 2016) and beyond. In addition, more widespread adoption of improved dry toilet technology could lessen the stigma of community based sanitary systems that are normally proposed for the underserved or unsewered cities in the Global South (Morales et al. 2014).

Toilet power is multifarious: it is the primary interface between the average citizen and the larger sanitary network, the largest consumer of indoor water, the largest domestic polluter, and the biggest contributor to reclaimed water supply. The power of the ordinary toilet is enlarged with every flush. Understanding the city as hybrid techno-nature helps to elucidate competing metabolisms and the dramatic difference that effluent's appearance makes in each environment. A description of local environmental conditions and specific urban metabolisms helps to explain neosanitarian and ecosanitarian subject positions in the context of the Southwest.

Coastal cities in California discharge treated wastewater into the Pacific Ocean. For example, when not recycled, Santa Monica Bay, depicted in Figure 3, is the receiving water for 300 million gallons per day (MGD) of the Los Angeles area's effluent. In effect, the toilet network of Los Angeles spans millions of people (including some participants in this study), the sewer system feeding into the sewage treatment plant, the effluent discharged miles off the coastline undersea; thus, enrolling sea life and surfers. In addition, the toilet network includes consumers of reclaimed water. For example, some of Los Angeles' effluent is pumped to West Basin Edward C. Little Water Recycling Facility where it is treated to various reclaimed water standards and sold to additional users (e.g., irrigation, industrial, or municipal). As it is redistributed it expands the toilet network of Los Angeles along the way. In California, environmental groups (e.g., Coastkeepers) favor potable reuse to minimize harm to the ocean environment and secure additional local water supply because effluent that is not recycled in coastal California is essentially lost to the ocean (i.e., physically unavailable).

In arid inland communities, such as southern Arizona, effluent is most often released into rivers and streams where it recharges the underground aquifers and replenishes some water supply. For example, in Tucson, Arizona excess effluent is released into the otherwise dry Santa Cruz River, as depicted in Figure 4. Effluent keeps the river flowing year-round near the wastewater treatment plant and sustains critical habitat necessary for many plants, birds, reptiles, mammals, and several endangered and threatened species (Sprouse 2005). The toilet network in Tucson includes local residents (including some participants in this study), the sewer system feeding into the sewage treatment plant, the various customers of non-potable reclaimed water, the 17 acres of artificially constructed Sweetwater Wetlands that were designed with the primary purpose of treating backwash water from the reclaimed treatment plant's filters, the effluent discharged into the Santa Cruz River, and all the species that thrive in this riparian environment. The effluent maintains essential habitat for a variety of wildlife and, as a result, the wastewater wetlands are a community amenity that serves as a site for aesthetic pleasure, experiential recreation, and environmental education in the desert. The City of Tucson promotes the benefits of Sweetwater Wetlands by publishing activity books and field guides for visitors (City of Tucson nd). The City's official support for reclaimed water is also evident in the Santa Cruz River Heritage Project, which began releasing 2.8 MGD of reclaimed water into the river several miles upstream in 2019. As a result, the Santa Cruz River now runs through downtown, which provides environmental and aesthetic benefits while recharging local aquifers. The physical relocation of reclaimed water also expands local water supplies because the City is recapturing water resources (via aquifer recharge) that would otherwise be lost to downstream users (i.e., physically and legally unavailable) (City of Tucson 2019). 


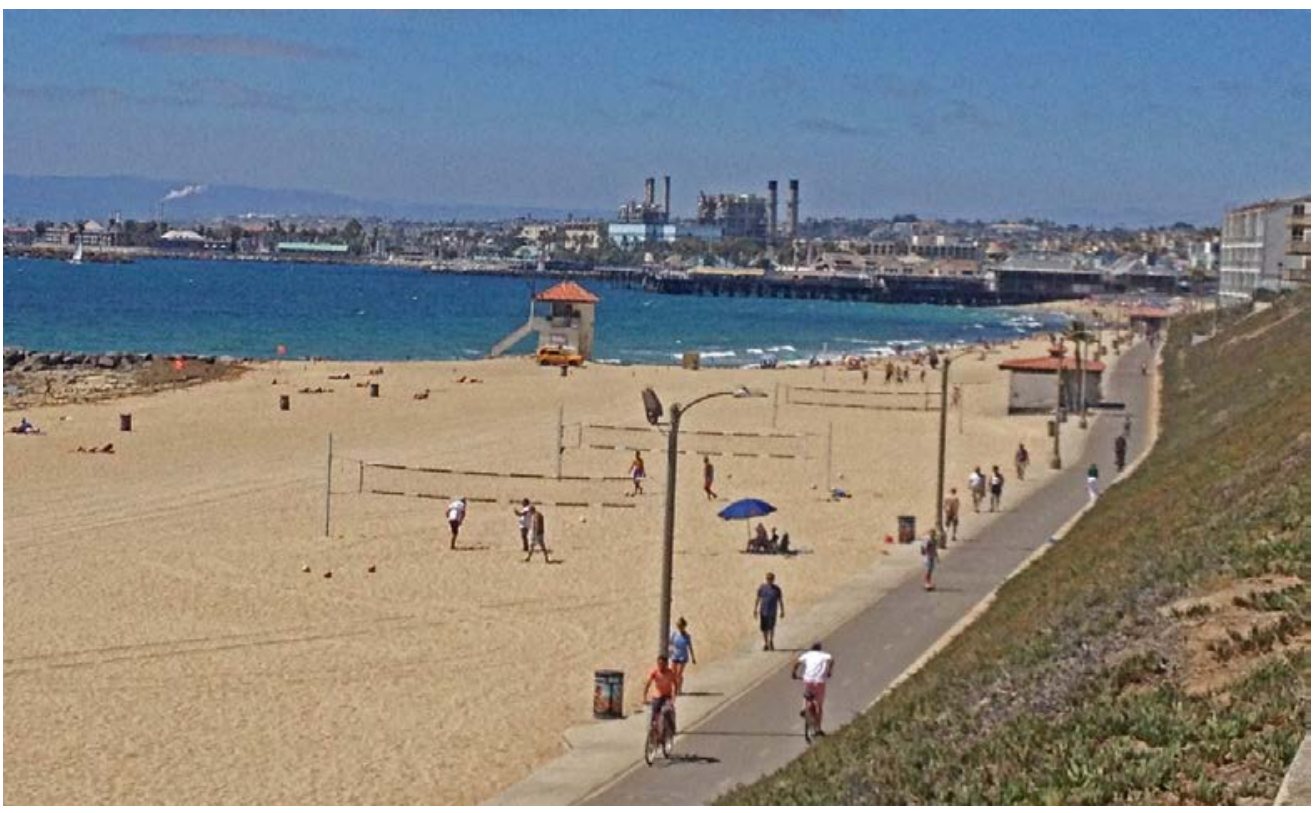

Figure 3: Santa Monica Bay in southern California, which serves as the receiving waters for excess effluent from the City of Los Angeles' Hyperion Treatment Plant, which began operations in 1894. The Marvin Braude Bike Trail, better known as The Strand, and Redondo Beach are pictured in the foreground. El Segundo Refinery, one of West Basin Edward C. Little Water Recycling Facility's customers, is seen in the background. Photo by author, July 2014.

The arid and semi-arid environments of the Southwest highlight unique issues regarding water quality and water quantity as well as the role effluent plays in the environment. While urban effluent is widely viewed as a nuisance and hazard on the coast of California, it is a resource in inland southern Arizona where the environment is an important 'unplanned user'. The role that effluent plays is qualitatively different in these two environments. These images illustrate that neosanitarians and ecosanitarians are embedded in different socionatural toilet networks. The results also complicate simple labels like sustainability or environmentalist because study participants live and work in distinctive surroundings, with different economies, and where reclaimed water has specific environmental uses, costs, values, and tradeoffs, all of which collectively produces different "environmentalisms."

Following Robbins' work on the American lawn, I suggest that urbanites are toilet people: that this very ordinary technology shapes environments and produces certain kinds of communities. Critically examining toilet power means acknowledging that modern toilets function best within a prescribed common sense: out of sight, out of mind. Transitioning away from infrastructure that supports flushing and forgetting will be as materially and culturally hard to abandon as urban transportation infrastructure designed primarily for automobiles. Engineers plan roads and sewers in tandem based on population projections and potential future flows of traffic, water, and sewage. While roads and waterworks are part of everyday urban life, most city dwellers only get a glimpse of water and sewer lines before the roads are laid, or if the roads are torn up for pipe repairs, yet they understand that roadways are spaces where our increased sense of independence is a negotiated interdependent relation with others (e.g., traffic, roadkill). This is true even for people who do not drive (e.g., cyclists, pedestrians). The sociality of sanitary systems is largely subterranean and less obvious to the average users (unlike the participants in this study). The participants in this study are unique toilet people precisely because they are knowledgeable about the tradeoffs of different water and sanitation infrastructures. 


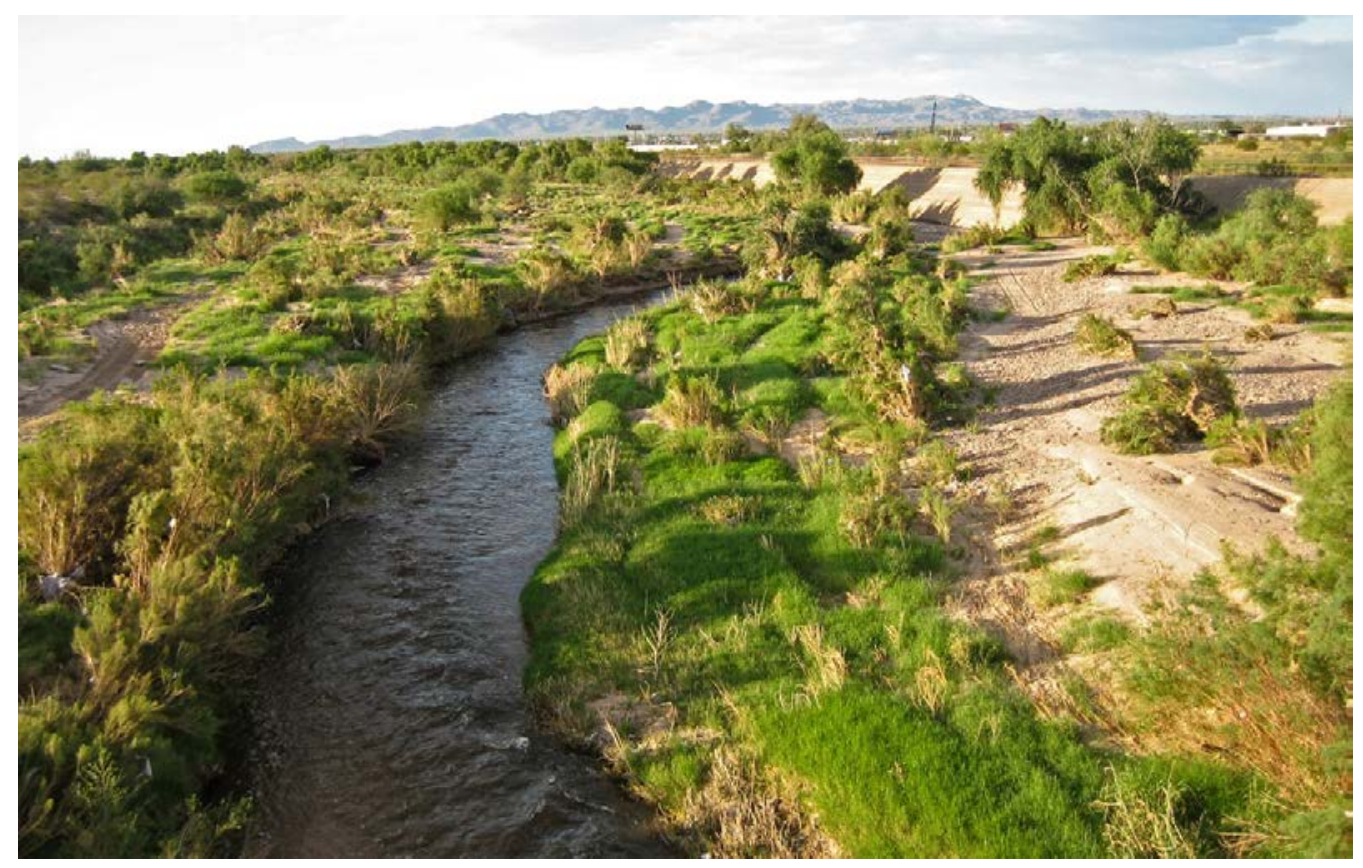

Figure 4: Santa Cruz River on the northwestern edge of Tucson, where 40 MGD gallons of effluent is discharged into an otherwise dry riverbed. Photo by author, February 2014.

Nevertheless, the subjective positions described in this article highlight how infrastructures operate through affective means: toilet power is influenced by embodied habits of practice with wide-ranging and cascading social and ecological impacts.

Neosanitarian and ecosanitarian subjects in this study are both comfortable with potable reuse, however their ideas of sustainability are not aligned. In sum, they prefer different forms of hydropolitics (e.g., tool power, tool people, tool places). The neosanitarians' position seeks to modify Progressive Era infrastructures with advanced water treatment technologies to extend the established order, preferably in the most efficient fashion - via DPR. The ecosanitarian perspective offers a revolutionary change from adapting to the current system. At the risk of being labeled as deviant, the ecosanitarian view hopes for a more intimate engagement with sanitation technology and excrement by the public as a means to disrupt the current waste-making routine. Ecosanitarians are not Luddites or environmental extremists that seek to create utopian societies as spaces as a means to resist state power or rising commercialism. On the contrary, the ecosanitarian position stresses complex relations associated with increased urbanization within or around established communities and they are also quite accepting of the technology of IPR. Their view demonstrates that although the neosanitarian view holds privileged position in the production of the urban waterscape, the path to potable reuse they propose is a nevertheless a contingent one.

The contribution of critical Q scholarship is that it can be applied to empirically identify how individual viewpoints cohere into shared perception profiles, while acknowledging that shared subjectivities are contingent, relational, and multiple. Unfortunately, there were fewer types of toilet people (i.e. factors) than I hoped to discover when I designed this study. The lack of diversity of opinion is indicative of a high level of organizational and institutional agreement in the water sector. This study does not represent all possible shared views, only those held in common by this select participant group. This study was limited to stakeholders who participated in water governance in the Southwest in some regard. Furthermore, the survey was similarly restricted to recommendations by those who were engaged in the reuse debate at the time. This narrow range of shared perspectives regarding water and wastewater planning is a dilemma, but it is a false dichotomy (as the six participants whose views did not significantly align with others indicate). For most urbanites in the US, 
water supply and disposal are local issues that few people currently know much about. The challenge is to increase the range of stakeholders engaged in the planning process. Ideally, greater engagement could contribute to creative new ideas (i.e. future possibilities) that would help to re-conceptualize our sanitary practices and ultimately change the insidious way we handle bodily waste, among other things.

\section{Conclusion}

This article contributes to political ecology and critical Q scholarship by exploring how water and sanitation technology shapes environments and subjectivities and by describing how different stakeholders consider the implications of planned potable water reuse. Two distinct sanitary subjectivities of key stakeholders in the Southwest — neosanitarian and ecosanitarian — were revealed through Q method analysis. The findings illustrate how different infrastructural assemblages produce different sets of hydropolitics. The neosanitarian toilet people are committed to potable water reuse as a means to expand urban water supply while reducing wastewater discharge into the larger environment. Ecosanitarian toilet people are idealistically hoping that composting toilet technology can produce more cooperative ecologies that are governed at much smaller scales, thus recognizing interdependencies between humans and non-humans and between local and global communities. The findings reveal the contested terrain of sanitation in the Southwest despite a trajectory that is predictability headed toward increasingly technologically sophisticated water treatments and neosanitarian expansion of potable water reuse. The ecosanitarian solution is largely incongruous with potable reuse precisely because decentralized dry sanitation systems eliminate the much of the wastewater that serves as the source for reclaimed water supplies.

Proposals to deliberately recycle water for potable purposes are at the forefront of water development, especially in the rapidly urbanizing arid and semi-arid regions of the Southwest. The results of this study illustrate how the different choices in toilet technology script different types of behavior, which, in turn, produces certain types of toilet people. The differing perspectives also reveal the toilet's role in forming certain kinds of communities and ecologies. My focus on infrastructure as a process of subject formation emphasizes that toilets are not inert. Toilets are negotiated daily with high levels of interaction. As the primary interface with the larger sanitation system, toilets shape relations with nature materially and mentally.

Toilet power is enlarged or diminished by specific toilet people in particular toilet places. Political ecology combined with Q methodology offers a framework for understanding human-environment relations that underscores process and allows for different sets of hydropolitics to be revealed. The analysis in this article suggests toilets are critically important infrastructures that facilitate environmental change. The respondents represent specific types of networked toilet people, as are you and I. If you accept that we are toilet people, that this very ordinary technology influences us, mediates our lives, and produces certain kinds of environments, the results of this study beg the question: what type of toilet do you feel comfortable being subject to?

\section{References}

Aliseda, A. 2006. Abductive reasoning - logical investigations into discovery and explanation. Dordrecht: Springer.

Beck, M.B., M. Thompson, D. Gyawali, S. Langan, and J. Linnerooth-Bayer. 2018. Viewpoint-pouring money down the drain: can we break the habit by reconceiving wastes as resources? Water Alternatives 11: 260283.

Buchel, S. and N. Frantzeskaki. 2015. Citizens' voice: a case study about perceived ecosystem services by urban park users in Rotterdam, the Netherlands. Ecosystem Services 12: 169-177. DOI: https://doi.org/10.1016/j.ecoser.2014.11.014.

City of Tucson. No date. Sweetwater Wetlands field guides. [accessed 26 Nov. 2019]

City of Tucson. 2019. The Santa Cruz River Heritage Project. [accessed 26 Nov. 2019]

Cousins, J.J. 2017a. Structuring hydrosocial relations in urban water governance. Annals of the American Association of Geographers 107(5): 1144-1161. DOI: https://doi.org/10.1080/24694452.2017.1293501. 
Cousins, J.J. 2017b. Volume control: stormwater and the politics of urban metabolism. Geoforum 85: 368-380. DOI: https://doi.org/10.1016/j.geoforum.2016.09.020.

Doshi, S. 2017. Embodied urban political ecology: five propositions. Area 49(1): 125-128. DOI: https://doi.org/10.1111/area.12293.

Eden, S.,A. Donaldson and G. Walker. 2005. Structuring subjectivities? using Q methodology in human geography. Area 37(4): 413-422. DOI: https://doi.org/10.1111/j.1475-4762.2005.00641.x

Environmental Protection Agency (EPA), (U.S). 2017 Potable reuse compendium. In Smith, C. (ed.). 2017 Potable reuse compendium. Office of Ground Water and Drinking Water.

Feinstein, L. and G. Daiess. 2019 plumbing the depths: Californians without toilets and running water. Oakland, Calif.: Pacific Institute. [accessed 26 Nov. 2019]

Fielding, K.S., S. Dolnicar and T. Schultz. 2018. Public acceptance of recycled water. International Journal of Water Resources Development 35(4): 551-586.

Iribarnegaray, M.A., M.F.E. de la Zerda, C.M. Hutton, C. Brannstrom, V.I. Liberal, W. Tejerina and L. Seghezzo. 2014. Water-conservation policies in perspective: insights from a Q-method study in Salta, Argentina. Water Policy 16(5): 897. DOI: https://doi.org/10.2166/wp.2014.159.

Jeffares, S., H. Dickinson and G. Hughes. 2012. iPOETQ (version 1.1). [accessed 26 Nov. 2019]. http://poetqblog.blogspot.co.uk.

Jepson, W., C. Brannstrom and N. Persons. 2012. "We Don't Take the Pledge": environmentality and environmental skepticism at the epicenter of US wind energy development. Geoforum 43(4): 851-863. DOI: https://doi.org/10.1016/j.geoforum.2012.02.002

Lehrer, N. and G. Sneegas. 2019. Beyond polarization: using Q methodology to explore stakeholders' views on pesticide use, and related risks for agricultural workers, in Washington State's tree fruit industry. Agriculture and Human Values 35(1): 131-147. DOI: https://doi.org/10.1007/s10460-017-9810-z

McEvoy, J. 2015. Can the adoption of desalination technology lead to aquifer preservation? A case study of a sociotechnical water system in Baja California Sur, Mexico. Water 7(10): 5224-5238. DOI: https://doi.org/10.3390/w7105224.

McKeown, B. and D. Thomas. 1988. Q methodology. Newbury Park: Sage.

Meehan, K., K.J. Ormerod and S. Moore. 2013. Remaking waste as water: the governance of recycled effluent for potable water supply. Water Alternatives 6(1): 67-85.

Meehan, K.M. 2014. Tool-power: water infrastructure as wellsprings of state power. Geoforum 57: 215-224. DOI: https://doi.org/10.1016/j.geoforum.2013.08.005

Millington, N. 2018. Producing water scarcity in São Paulo, Brazil: the 2014-2015 water crisis and the binding politics of infrastructure. Political Geography 65: 26-34. DOI: https://doi.org/10.1016/j.polgeo.2018.04.007

Morales, M.D.C., L. Harris and G. Öberg. 2014. Citizenshit: the right to flush and the urban sanitation imaginary. Environment and Planning A 46(12): 2816-2833. DOI: https://doi.org/10.1068/a130331p

Monstadt, J. 2009. Conceptualizing the political ecology of urban infrastructures: insights from technology and urban studies. Environment \& Planning A 41(8): 1924-1942. DOI: https://doi.org/10.1068/a4145

National Research Council (NRC). 2012. Water reuse: potential for expanding the nation's water supply through reuse of municipal wastewater. Washington DC: National Academies Press.

Nost, E., M. Robertson, and R. Lave. 2019. Q-method and the performance of subjectivity: reflections from a survey of US stream restoration practitioners. Geoforum 105: 23-31. DOI: https://doi.org/10.1016/j.geoforum.2019.06.004

Ormerod, K.J. 2016. Illuminating elimination: public perception and the production of potable water reuse. Wiley Interdisciplinary Reviews: Water 3(4): 537-547. DOI: https://doi.org/10.1002/wat2.1149

Ormerod, K.J. 2017. Common sense principles governing potable water recycling in the southwestern US: examining subjectivity of water stewards using Q methodology. Geoforum 86: 76-85. DOI: https://doi.org/10.1016/j.geoforum.2017.09.004. 
PQMethod. 2014. PQMethod (version 2.35. http://schmolck.org/qmethod [accessed 26 Nov. 2019]).

Radonic, L. 2019. Becoming with rainwater: a study of hydrosocial relations and subjectivity in a desert city. Economic Anthropology 6: 291-303. DOI: https://doi.org/10.1002/sea2.12146.

Radonic, L. and S. Kelly-Richards. 2015. Pipes and praxis: a methodological contribution to the urban political ecology of water. Journal of Political Ecology 22(1): 389-409.

Robbins, P. 2007. Lawn people: how grasses, weeds, and chemicals make us who we are. Philadelphia: Temple University Press.

Robbins, P. and R. Krueger. 2000. Beyond bias? the promise and limits of Q method in human geography. The Professional Geographer 52(4): 636-648. DOI: https://doi.org/10.1111/0033-0124.00252

Robbins, P. and B. Marks. 2009. Assemblage geographies. In Smith, S.J., S. Marston, R. Pain and J.P. Jones III (eds.). The SAGE handbook of Social Geography.Thousand Oaks: Sage.

Speer, J. 2016. The right to infrastructure: a struggle for sanitation in Fresno, California homeless encampments. Urban Geography 37(7): 1049-1069. DOI: https://doi.org/10.1080/02723638.2016.1142150.

Sneegas, G. 2019. Making the case for critical Q methodology. The Professional Geographer. In press. https://doi.org/10.1080/00330124.2019.1598271

Sprouse, T. 2005. Water issues on the Arizona-Mexico border, the Santa Cruz, San Pedro and Colorado Rivers. Tucson: Water Resources Research Center. Tucson: University of Arizona.

Ward, L. 2013. Eco-governmentality revisited: mapping divergent subjectivities among integrated water resource management experts in Paraguay. Geoforum 46: 91-102. DOI: https://doi.org/10.1016/j.geoforum.2012.12.004

Watts, S. and P. Stenner. 2012. Doing Q methodological research: theory, method and interpretation. Los Angeles: Sage. 